\title{
A BRIEF LITERATURE INVESTIGATIONS ON FOLIAR PLANT NUTRITION AND ITS FUNCTION IN THE PROTECTION OF HORTICULTURAL CROPS
}

Author(s):

M. Massimi, L. Radócz

Affiliation:

Kerpely Kálmán Doctoral School of Crop Sciences and Horticulture, Institute of Plant Protection, University of Debrecen, H-4032 Debrecen, Hungary

\section{Email address:}

mohunnad.massimi@moa.gov.jo, radocz@agr.unideb.hu

Abstract: Over the most recent couple of years, human health disintegration and ecological contamination because of unnecessary utilization of engineered agrochemicals have become a developing concern. The objective of this review essay was to shed the light on the foliar plant nutrition practice, especially in tomato and pepper production. The article depended on research articles and extension reports. The article covered significant issues arising in foliar plant application incorporate integrated pest management strategies, plant nutrition complex connection with biotic and abiotic stresses, merits and challenges of foliar application method, and close literature review for tomato and pepper foliar application. In summary, the use of foliar application techniques in horticultural plant production is a crucial strategy for integrated pest control, sustainable environmental practices, and balanced food production. It is recommended that agricultural science research be extended to enhance integrated management practices and integrated plant protection.

Keywords: foliar plant; horticulture; IPM; organic production

\section{Introduction}

There have been many questions recently raised about the foliar application technique. Some researchers include it within the methods of integrated pest control, and others as part of organic farming procedures. Besides, there is an implicit relationship between the health of horticultural plant crops and nutrients deficiency. For example, modern science seeks to uncover the hidden relationship between drought stress and the infection of tomatoes and peppers with powdery mildew disease and the use of foliar fertilizers as a precautionary procedure to maintain growth and production.

The goal of this review essay was to shed light on the foliar application practice, particularly in the production of tomatoes and peppers. The article discussed major issues related to a foliar application, including integrated pest control methods, complex plant nutritional status, and linkages with biotic and abiotic stresses. Advantages and challenges of foliar application technique, and a close analysis of the literature on tomatoes and peppers.

\section{Integrated pests management strategies and tactics}

Integrated Pest Management (IPM) is an accessible and environmentally sensitive approach to pest management. It uses natural predators, pest-resistant plants, and other means of maintaining a healthy environment to minimize dependency on chemical pesticides.

The concept of integrated pest management (IPM) was first suggested in 1957 as a concept that promoted the use of biological control and effective agricultural practices before the use of chemical pesticides for pest control. Integrated pest management (IPM) or integrated plant protection (IPP) relies on the main principles: growing a healthy crop, managing natural enemies, constantly monitoring fields, and turning farmers into experts (FAO, 2005). In 1959 a published paper entitled "The Integration of Chemical and Biological Control of the Spotted Alfalfa Aphid". Stern et al., (1959) gave the first statement of theory concerning the integrated control term or definition. The philosophy says that "whatever the reasons for our increased pest problems, it is becoming more and more evident that an integrated approach, utilizing both biological and chemical 
control, must be developed in many of our pest problems if we are to rectify the mistakes of the past and avoid similar ones in the future".

Agri-technical, mechanical, biological, chemical, and economic threshold levels are all part of the concept of integrated pest management. Stern et al., (1959) described integrated control as applied pest control, which incorporates and integrates biological and chemical control and use economic thresholds to decide when chemical control should be used to prevent pests from reaching economic injury levels.

Integrated pest control has grown into a modern scientific term that involves insects, plant pathogens, weeds, and vertebrate pests. For example, Massimi (2017) concluded that integrated weed management (IWM) plans usually consist of several methods that are divided into biological, cultural, and physical (mechanical) and chemical. Physical approaches include the use of mulches, manual weeding, tillage, flame, soil steam sterilization, and soil solarization. Cultural techniques, primarily crop rotation, are used to rotate crops with crops that kill weeds by choking them out. This is a way to avoid the use of toxic chemical herbicides and to reap the advantages of crop rotation. Biological weed control regiments may consist of biological control agents, biological herbicides, the use of grazing animals, and the protection of natural predators.

Integrated pest management has several approaches to protect horticultural crops, such as choice of diseasetolerant varieties, solar solarization, ventilation of the greenhouse, reduction of the plant density, irrigation to minimize drought severity, removal of old and large infected leaves, collect and removal of infected fruits, avoid growing more than one variety in the same greenhouse, long crop rotations, hand weeding, safely sterilized seeds, use of sterilized manure, biological control, tillage, trap crops, optimal plant nutrition, and irrigation scheduling, and drainage management.

\section{Plant nutrition relation with biotic and abiotic stresses}

Other fundamental principles for integrated pest control are soil fertility management and irrigation and drainage management. In 2005, the FAO (Near East IPM Project) proposed that decision-making in integrated pest management would require an overview of the agricultural environment with all its components, including plants, insects, diseases, natural enemies, weeds, soil, and climate.

It is well established that there is a close relationship between the nutrient supply of the plant nutrients and the resistance to diseases. In other words, disease control, the value of supply of the nutrients are becoming an increasingly important part of sustainable plant defense. For example, it is well recognized that the plant protection mechanism against pathogens with optimal phosphorus and potassium nutrient supplies is much stronger than plants with inadequate nutrient supplies. Huber and Haneklaus (2007) concluded that nutrient management by amendment, improved genetic quality, and environmental modification is a significant cultural control of plant diseases and an integral component of successful production agriculture. Disease resistance is genetically regulated but mediated by physiological and biochemical processes linked to the nutritional status of the plant or pathogen. It has been stated that resistance of wheat and flax to rust, and corn to Stewart's wilt, maybe have been lost under potassium deficiency (Huber and Arny, 1985). Fusarium wilt of tomatoes and cabbage yellows, Stewart's wilt of corn, and downy mildew of tobacco are increased by potassium when there is an imbalance of other nutrients (Huber and Arny, 1985). The association of tissue nutrients in diseased compared to healthy, plants have also provided insight into the interactions between nutrients and diseases, and detailed examples are recorded for most important nutrients. The resistance of rice to blast, sheath blight, brown spot, and stem rot is associated with high levels of silicon in plant tissues (Savant et al., 1997).

Iowa State University extension and outreach reported a recent experiment published a recent experiment performed by Wright and Lenssen (2013) with evidence of many pros effects on plant growth of substances such as humic and fulvic acids. At low concentrations, humic acid increased the vegetative growth of soybean and corn. Stimulation of root growth can therefore increase plant resistance to disease, plant response to herbivores and nematodes, and water stress caused by drought. Massimi et al., (2019) performed an extension analysis on green bean (the name of the variety is Valentino) and a variety of green cowpea (California Black Eye). An organic liquid fertilizer product containing 12 percent humic acid and 3 percent fulvic acid should be applied with irrigation water after two weeks of planting and repeated every two weeks during the growing season. The latter research recommended that farmers use one of the most essential organic products manufactured in Jordan, a liquid compound containing the active ingredient organically coated copperphosphate. It has 10 percent copper and 10 percent phosphorus. The comparative advantage of this commodity is that it is used as a fertilizer for plant nutrition where pulses such as calcium require phosphorus. 
It can also be applied with foliar spray at a rate of 100-125 mm per 200 liters of water or with irrigation water at a rate of 500-1000 mm per 0.1 hectares. The active ingredient is an organically coated copper-phosphate that is persistent in plant leaves and soil and has a systematic effect that stimulates the development of phytoalexins and strengthens the walls of plant cells and plant tissues that stimulate plant growth and prevent plant dwarfing. Prevents the penetration of fungus hyphae and bacteria, encircles infected spots with halo and covers the aerial and ground sections of the plant. It is used to protect plants from diseases such as anthracnoses, molds, rots, mildews, and blights. It may also be used to combat fungal wilts (Fusarium spp. and Verticillium spp.), and fungal damping off (Fusarium spp, and Pythium spp.).

The addition of nutrients to the soil is generally defined by the negative availability of the nutrients. Each crop requires an adequate soil $\mathrm{pH}$ for growth and development. The supply of nutrients for the crop is also linked to the optimum $\mathrm{pH}$ of the soil. Cornell University Cooperative Extension released a fact sheet in the agronomy fact sheets series in 2005. The recommended soil $\mathrm{pH}$ range for optimal corn growth has been reported (5.8-6.2), and soybean has been reported (6.6-7). Neutral soil $\mathrm{pH}$ (around 7) is ideal for the availability of nitrogen, phosphorus, potassium, sulfur, calcium, and magnesium availability. However, iron, manganese, copper, zinc, and boron are more readily available in acidic soils.

Lack of calcium combined with less sap movement in the xylem of tomato plants resulting from a water deficit can affect the production of xylem tissue during the development of the fruit. This hinders the movement of calcium into the fruit by the xylem and as a result, the blossom-end rot may occur and may affect the distribution of calcium inside the damaged fruit, with healthy fruits providing more soluble calcium than the fruits presenting this physiological disorder (Flores, 2018). Also, calcium administered to the plant via foliar application has been to be essential for resistance to bacterial wilt and fusarium crown rot resistance in tomatoes (Woltz et al., 1992) cited in (Singh et al., 2013). Calcium-containing sprays containing calcium can also be used to avoid blossom end rot in tomatoes (Singh et al., 2013).

Powdery mildew (Leveillula taurica) is a severe fungal disease, although it is a fungus that can grow very naturally in dry conditions. It lives at temperatures between $10-12{ }^{\circ} \mathrm{C}$, but the optimum conditions are located at a $30^{\circ} \mathrm{C}$. It is considered a significant disease of tomatoes in the vegetative, flowering and fruiting stages. As in the case of sweet corn (Plantix App 3.3.0, PEAT, 2020) reported by (Strey, 2020). However, pepper is affected both in the vegetative and in the flowering phases. Powdery mildew affects soybeans in the seedlings, in the vegetative, flowering, and fruiting stages. Amacher et al., (2000) of Utah State University reported that as the soil dries, salts become concentrated in the soil solution, increasing salt stress. Salt problems are therefore more serious under hot dry conditions than under cool, humid conditions. It is reasonable to conclude that drought and salinization increase the chance of plants becoming infected with powdery mildew.

However, contradictory reports have shown that (Oidium neolycopersici) induces extreme powdery mildew on all aerial parts of tomato, except fruit. The latter research findings indicate that the combination of high temperatures and low relative humidity can help to reduce $O$. neolycopersici powdery mildew in greenhouse tomatoes (Jcob et al., 2008). Kafle et al., (2017) experimented with tomato as a model plant to improve its resistance to powdery mildew disease (Oidium spp. and Leveillula spp.) by stimulating its innate immune system at an early seedling stage due to poor drought shocks. Plants have been treated with three degrees of drought stress: low, medium, and high ( 75 percent, 50 percent, and 25 percent field capacities respectively). Drought treated plants displayed an elevated level of hydrogen peroxide (H2O2) and after disease inoculation, these plants had a higher total phenol content and less area under the disease progression curve with higher biomass compared to the control plants; improved resistance to the powdery mildew. It was concluded that immune provided by hydrogen peroxide and phenolic compounds may be responsible for developing the resistance of powdery mildew in tomatoes.

As a result, foliar sprays are increasingly used in horticulture to increase crop yield and quality, as well as to improve plant production under possible abiotic and/ or biotic stresses (Rengel, 2020).

\section{Merits and challenges of foliar application technique}

On the other hand, in comparison to supplying nutrients to crops via the soil, a new technique called a foliar application or foliar fertilization has emerged. The soil application of fertilizers is mainly based on soil tests, whereas the application of foliar nutrients is largely based on visual foliar symptoms or plant tissue checks. The correct diagnosis of nutrient deficiency is therefore necessary for effective foliar fertilization (Fageria et al., 2009). 
Patil and Chetan (2018) noted that foliar feeding has been widely used and accepted as an important part of crop production, especially in horticultural crops. While not as widespread in agronomic field crops, The object of foliar feeding is not to substitute soil fertilization. Supplying the key nutrient needs of a plant (nitrogen, phosphorus, and potassium) is the most efficient and cost-effective by soil application. The foliar application has, however, proven to be an excellent method of supplying plant requirements for secondary nutrients (calcium, magnesium, and sulfur) and micronutrients (zinc, manganese, iron, copper, boron, and molybdenum).

Patil and Chetan (2018) reported the advantages of foliar application in some areas that aid in the rapid correction of nutrient deficiency:

1. It helps to fix nutrient deficiency quickly.

2. Foliar spraying may be mixed with other sprayings such as insecticides.

3. When the soil is low in nutrients, the application of foliar application is advantageous.

4. When a rapid growth response is needed, the foliar application can be sprayed.

5. It will aid during the high phosphorus and potassium fixation.

6. A foliar spray may be applied when adverse conditions such as root rot disease, dryness, etc... have been in the field.

7. A foliar spray can also be used if there is insufficient moisture in the topsoil to absorb the nutrients from the roots of the plant.

8. Just use small amounts of fertilizer.

9. Improved parameters of yield and quality efficiency.

Haytova (2013) recorded the merits of foliar application. The technique promotes rapid absorption of mineral nutrients, preventing the occurrence of soil interactions that minimize root uptake due to soil immobilization. It can correct physiological disorders caused by nutrient deficiencies. Foliar application can be used as an integrated pest control practice for the cultivation of many types of vegetables (Haytova, 2013). It can increase crop yields, reduce plant protection costs, and reduces soil and water contamination.

Several studies have reported that the foliar use of nitrogen, phosphorus, and potassium has improved the nutrient uptake of sweet corn. Diver et al., (2001) stated that foliar feeding, used in conjunction with a chlorophyll meter, is a yield-enhancing production technique for corn. This method can be seen as a sophisticated organic farming practice. Another research conducted by (Muktamar et al., 2016) concluded that there is a rise in rates of foliar application of liquid organic fertilizer and nitrogen uptake by sweet corn, but not phosphorus and potassium, in the closed agricultural system. One of the most prominent researchers in this field observed through laboratory analysis of leaves, in the case of magnesium and zinc supply, foliar fertilizers have been able to prevent the production of nutrient deficiency in sweet corn (Racz and Radocz, 2020).

Theoretically, foliar fertilization is more environmentally sustainable, and targeted than soil nutrients fertilization, since nutrients can be transmitted to plant tissues during critical stages of plant growth. However, while the need to remedy a deficiency may be well defined, the effectiveness may be far more unpredictable. Since all aerial plant parts are protected by a hydrophobic cuticle that restricts the bidirectional exchange of water, solutes, and gases between the plant and the atmosphere. However, the nutrient solutions can be absorbed by cracks, stomata, and lenticels (Fernandez et al., 2013).

Stomata can play a major role in the absorption of nutrient solutions applied to leaves and foliages. Mineral element carriers may be added on their own or in a combination mixture with a variety of adjuvants that may boost contact characteristics, absorption rate, and surface distribution of the active ingredient(s) when applied to the leaves. Surfactants are an important, widely used group of adjuvants that reduce the surface tension of nutrient solutions and generally increase their wetting and spreading to the plant surface. Some adjuvants, such as surfactants, penetration synergists, stickers, and humectants, can increase and improve the rate of uptake, retention, and retardation of foliar nutrient sprays drying (Fernandez et al., 2013).

Fernandez et al., (2013) reported that light, humidity, and temperature could affect foliar absorption by affecting plant metabolic status and could therefore cause alteration of photosynthesis, stomatal opening, respiration, leaf expansion, and sink activity, thereby altering the energy and metabolic activity involved in the uptake, assimilation and subsequent transport of foliar-applied nutrients. In conclusion, short-term and long-term environmental interactions have long-term effects on the physical and chemical characteristics of leaves and plants.

From this point on, it can be seen that long-term interactions of abiotic influences, such as relative humidity, light, and temperature, with the biotic stresses such as pests, can alter the efficacy of the foliar application. It has effects on plant nutrient status that changes the structure of the leaf, the physiology of the leaf, and can 
alter leaf assimilation of foliar applied-nutrients (Fernandez et al., 2013).The process of absorption and biological assimilation of leaf-applied substances is so complex, and many anatomical, physiological, environmental, and physicochemical factors may have a positive or negative effect on plant response to the treatment (Rengel, 2020).

\section{A close review of foliar application in tomato and pepper}

Tomato (Lycopersicum esculentum Mill.) and pepper (Capsicum annuum L.) are important summer warmseason horticultural crops. Németh and Ehret-Berczi (2014) reported that the production of greenhouse vegetables is a key horticultural field, accounting for a substantial proportion of the production value of horticultural products and contributing to the minimization of imports in Hungary. Greenhouse vegetables account for 5-6 percent of the total area of vegetable production in Hungary, where tomatoes are the most important vegetable crop for greenhouse vegetables after paprika. In addition, the agricultural survey conducted in Jordan by the Department of Statistics (2017) confirmed that tomatoes in Jordan are a major vegetable crop. Of the total area (37695.6 ha) cultivated with all other vegetables, the total area grown for tomato cultivation in 2017 is (12194.5 ha). A similar pattern was recorded in the oldest agricultural survey in Jordan in 1995, with the tomato region representing a greater area of (11104.6 ha) than the total area of vegetables (42930.9 ha). Massimi and Al-Bdour (2018) reported that according to statistics from the Jordan Government's (2016) Statistics Department, the total area of vegetables in Jordan was approximately 50579 hectares including open and covered crops, most of which included tomatoes, squash, eggplant, cucumbers, potatoes, cabbage, cauliflower, pepper, and faba-beans. In 2017, tomatoes, squash, eggplant, cucumber, potatoes, paprika, and cauliflower were the highest in Jordan (Department of Statistics, 2017). The statistics on Hungary and Jordan show the importance of tomatoes and pepper plants.

On the opposite side, the absorption of nutrients from water solutions and foliar applications on the leaves and their physiological impacts on the plant have been the focus of study for many decades. The first reports for foliar applications are available in France during the 1844 year (Haytova, 2013). After these first publications, several other studies have given rise to the popularity of the foliar application.

Yildirim (2007) studied the impact of foliar and soil fertilization with humic acid (HA) on the growth and yield of tomatoes under greenhouse conditions in 2004 and 2005. Tomato plants have been treated with soil and foliar humic acid applications at various concentration levels of $\left(0 \mathrm{ml} \mathrm{l}^{-1}, 10 \mathrm{ml} \mathrm{l}^{-1}\right.$, and $\left.20 \mathrm{ml} \mathrm{l}^{-1}\right)$. During the vegetation season, humic acid was sprayed four times at 10-day intervals after three weeks of planting. In addition, 0,10 , and $20 \mathrm{ml} \mathrm{l}^{-1}$ humic acid solutions were applied to the root region of the plant four times during the vegetation cycle at 10-day intervals three weeks after planting. Foliar applications have led to a higher content of leaf and stem dry matter than control. Fruit characteristics, including fruit diameter, fruit height, mean fruit weight, and fruit number per plant, were positively influenced by both foliar and soil treatments. In the same way, treatments increased the early yield of tomatoes compared to control. The yield of tomatoes was significantly affected by soil and foliar applications. The highest yield was observed occurred in the foliar treatment of $20 \mathrm{ml} \mathrm{l}^{-1}$. The study concluded that the concentration of $20 \mathrm{ml} \mathrm{l}^{-1}$ of humic acid sprays could be successfully used to achieve better growth and yield in the tomato plant. Premsekhar and Rajashree (2009) found that foliar feed application of 5 N-P-K sprays (19:19:19) recorded the tallest tomato plant (the hybrid name is $C O T H 2$ ), highest fruit weight, the highest fruit number per one plant, fruit yield, and the highest cost-benefit ratio (BC). This may be due to the higher fruit yields obtained in the foliar application treatment.

Further in-depth studies demonstrated the effectiveness of the foliar application technique. It has previously been mentioned that zinc deficiency is considered to be one of the nutritional constraints for the development of vegetable crops, in particular tomato plants. Ejaz (2012) tried and tested tomato cultivar (Sahil). Seedlings were planted on raised beds under polytunnel with a uniform spacing of $45-\mathrm{cm}$ plant-to-plant distance and $75-\mathrm{cm}$ as bed-to-bed distance. $\mathrm{ZnSO} 4$ was used as a source of $\mathrm{Zn}$ (10 percent or 12 percent) and Urea as a source of nitrogen $(\mathrm{N})$ (1 percent and 2 percent). The results showed that the foliar application of either $\mathrm{Zn}$ or $\mathrm{N}$ separately at both concentrations increased, growth, yield, and quality of tomato cultivar. However, the most prominent result showed that the combined use of both $\mathrm{Zn}$ (12 percent) and $\mathrm{N}$ ( 2 percent) increased the growth, yield, and quality of tomato plants. This research concluded that the combined use of $\mathrm{Zn}$ and $\mathrm{N}$ in foliar applications can be a viable practice in the production of tomato plants. Li et al., (2018) published an article in the Journal of Experimental Botany comparing the absorption of $\mathrm{Zn}$ when supplied as either $\mathrm{ZnSO} 4$, nano- $\mathrm{ZnO}$, or bulk- $\mathrm{ZnO}$ and found that the absorption of $\mathrm{ZnSO} 4$ was around 10 -fold higher than that of nano- 
and bulk- $\mathrm{ZnO}$, indicating that it was mainly absorbed as soluble $\mathrm{Zn}$. The latter study investigated the role of trichomes in the absorption of foliar-applied zinc fertilizers in tomatoes and soybeans.

Other findings indicated that the foliar application of $\mathrm{Zn}$ on two tomato cultivars (Blizzard), and (Liberto) may overcome the negative effects of zinc deficiency on plant growth when applied to the optimum range (Kaya and Higgs, 2002). However, several other contradictory studies have shown other findings. The research carried out in Turkey was to investigate the effects of copper application on calcareous soil and leaves on the yield and growth of tomato plants. Copper was first applied to soil as $\mathrm{CuSO} 4.5 \mathrm{H} 2 \mathrm{O}$ in three different levels $\left(0,1000\right.$, and $2000 \mathrm{mg}$ of copper $\left.\mathrm{kg}^{-1}\right)$ and then to leaves at three different frequencies (no application, biweekly, and weekly application) in pot experiments performed in a computer-controlled greenhouse. Total yield, the number of fruits, dry root weight, and plant height decreased with increasing application of copper $(\mathrm{Cu})$ to the soil. Increased levels of copper added to the soil and leaves resulted in decreased final fruit count, dry root weight, and plant height at $4^{\text {th }}, 5^{\text {th }}$, and $6^{\text {th }}$ weeks. The combined applications of copper to soil and leaves may be more deleterious to plants than when copper is applied only to soil or leaves (Sonmez et al., 2006).

Wittwer et al., (1963) cited in Singh et al., (2013) reported that plant foliage resistance to foliar application varies from plant to plant. However, the resistance of tomato and pepper foliage resistance was close $(0.48$ $0.72 \mathrm{Kg}$ of Urea sprays $100 \mathrm{l}^{-1}$ of water). Singh et al., (2013) also compared the timing and application rates of sulfur foliar in different crops. The researchers concluded that the tomato plant can be sprayed 3 times at the stage of the first sign of bloom, 21 days after the first spray, and 14-21 days after the second spray. The foliar sulfur spray was at a rate of $\left(0.18-0.36 \mathrm{Kg} \mathrm{Acre}^{-1}\right)$ for each tomato spray. However the pepper plant recommended to be sprayed at the bud formation stage, 10-14 days after the first spray, and 10-14 days after the second spray at a rate of $\left(0.11-0.23 \mathrm{Kg} \mathrm{Acre}^{-1}\right)$ per each sulfur spray time.

Plants such as tomatoes and peppers need high levels of magnesium for optimum growth. However, the effects of magnesium deficiency cannot be seen by plants until it is serious. The foliar application of a 2 percent solution of $\mathrm{MgSO} 4$ to tomatoes also relieved magnesium deficiency and improved crop yields (Singh et al., 2013). Nannette (2011) recommended foliar spraying of magnesium sulfate hydrate (epsomite) in tomatoes and peppers for maximum product growth, yield, and quality.

There is a complex relationship between abiotic stresses such as drought and salinity and plants' susceptibility to diseases. It highlights the importance of foliar application as one of the integrated pest management methods for the treatment of diseases in conditions of heat stress, drought stress, and salinization of soil such as Jordan. It is important to note the indirect relationship between drought stress and other forms of stress, i.e. high temperatures may trigger drought stress, and thus salinity stress. It can be understood that drought stress is the most significant abiotic stress in horticultural crops. Utah State University Amacher et al., (2000) stated that as the soil dries, salts are accumulated in the soil solution, increasing salt stress. Therefore in hot dry conditions, salt problems are more extreme than in cool, humid conditions. Vegetables are succulent, most of the plants are sensitive to drought stress, particularly from flowering to stage of seed growth. It has been stated that corn, soybeans, beans, and peas are considered to be moderately sensitive to water stress, while tomatoes are part of a community group sensitive to severe drought (Nemeskeri and Helyes 2019). A greenhouse experiment was performed to investigate the effects of potassium (K) foliar application on pepper plants grown with various irrigation salinity waters (3000 and $6000 \mathrm{ppm}$ as compared to tap water with a salinity level of $300 \mathrm{ppm}$ ). In contrast to those of plants irrigated by tap water, irrigation with high salinity water decreased plant height, biomass production, and fruit yield. For the plants under the maximum salinity irrigation (6000 ppm), the most serious impact was compared to plants under moderate salinity irrigation $(3000 \mathrm{ppm})$. Foliar application of potassium monophosphate (KMP) at $200 \mathrm{ppm}$ concentration increased plant growth, biomass production, and fruit yield. This showed that to some degree, foliar application of KM mitigated the adverse effects of high salinity water irrigation on the growth of pepper plants and fruit yield (Hussein et al., 2012).

\section{Conclusions and recommendations}

In short, the use of foliar application techniques in the development of horticultural plants is a critical strategy for integrated management of pests, sustainable practices in the environment, and healthy food production. To improve integrated management practices and integrated plant protection, it is proposed that agricultural science research be expanded. This requires specialized research to discover the ability of a foliar application to treat pests that spread in certain environmental conditions. It is recommended to investigate the relationship 
between the development of powdery mildew fungal disease, and drought stress on tomatoes and peppers in Hungary and Jordan.

\section{Acknowledgments}

This study was carried out with help of the University of Debrecen, Doctoral School of Horticultural Sciences, Institute of Plant Protection, supported by the Stipendum Hungaricum Scholarship, Hungary in 2020.

\section{References}

[1] Amacher, J, K., Koenig, R., \& Kitchen, B. (2000). Salinity and plant tolerance. Archived USU Extension Publications, Utah State University.

[2] Cooperative Extension. (2005). Soil pH for field crops. Department of Crop and Soil Sciences, Cornell University.

[3] Department of Statistics. (2017). Survey. Agriculture. DOS website, Government of Jordan (accessed on October 2020).

[4] Diver, S., Kuepper, G., \& Sullivan, P. (2001). Organic sweet corn production. ATTRA Project. National Center for Appropriate Technology. Rural Business-Cooperative Service, U.S. Department of Agriculture. USDA.

[5] Ejaz, M., Waqas, R., Ayyub, C.M., Butt, M., Shuaib-ur-Rehman, F., Bashir, A.M. (2012). Efficacy of zinc with nitrogen as foliar feeding on growth, yield and quality of tomato grown under poly tunnel. Pakistan Journal of Agricultural Sciences, 49(3), 331-333.

[6] Fageria, N. K., Barbosa Filho, M.P., Moreira, A. \& Guimares, C.M. (2009). Foliar fertilization of crop plants. Journal of Plant Nutrition, 32, 1044-1064.

[7] FAO, Near East IPM Project. (2205). Daleel mushrifee madaris Al-mozareen Al-haqlyah, Part Two, (Arabic).

[8] Fernandez, V., Sotiropoulos, T., \& Brown, P. (2013). Foliar fertilization: scientific principles and field practices. International fertilizer industry association (IFA), Paris, France, 2013. First edition.

[9] Flores, M. (2018). Response of tomato plants to water stress and calcium nutrition. M.S.thesis.

[10] Haytova, D. (2013). A review of foliar fertilization of some vegetables crops. Annual Review \& Research in Biology, 3(4), 455-465.

[11] Huber, D.M, \& Arny, D.C. (1985). Interactions of potassium with plant disease. In R.D. Munson, W.D. Bishop (Eds.), Potassium in agriculture: proceedings of an International Symposium. Madison Wis. American Society of Agronomy, 467-488.

[12] Huber, D.M., \& Haneklaus, S. (2007). Managing nutrition to control plant disease. Landbauforschung Völkenrode,4 (57), 313-322.

[13] Hussein, M.M., EL-Faham, S.Y., \& Alva, A.K. (2012). Pepper plants growth, yield, photosynthetic pigments, and total phenols as affected by foliar application of potassium under different salinity irrigation water. Agricultural Sciences, 3(2), 241-248.

[14] Jacob, D., Rav David, D., Sztjenberg, A., \& Elad, Y. (2008). Conditions for development of powdery mildew of tomato caused by Oidium neolycopersici. Phytopathology, 98, 270-281.

[15] Kafle, M., Pandey, A., Shrestha, A., Dhital, B., Basi-Chipalu, Sh., \& Basi, S. (2017). Induced abiotic stress: prospects of powdery mildew resistance in tomato plants. Journl of Plant Physiology \& Pathology, 6 (1).

[16] Kaya, C., \& Higgs, D. (2002). Response of tomato (Lycopersicum esculentum L.) cultivars to foliar application of zinc when grown in sand culture at low zinc. Scientia Horticulturae, (93), 53-64.

[17] Li, C., Wang, P., Lombi, E., Cheng, M., Tang, C., Howard, D.L., Menzies, N.W., \& Kopittke, P.M. (2018). Absorption of foliar-applied $\mathrm{Zn}$ fertilizers by trichomes in soybean and tomato. Journal of Experimental Botany, 69 (10), 2717-2729.

[18] Massimi, M. (2017). Importance of field extension training for farmers of alfalfa (Medicago sativa L.) to adopt weed control techniques. Asian Journal of Agricultural Extension, Economics and Sociology, 20 (3), 1-7.

[19] Massimi, M., \& Al-Bdour, A. (2018). A short scientific note on the horticultural crops optimum planting dates in Jordan. Egyptian Journal of Horticulture, 45(2), 337-340. 
[20] Massimi, M., Haseeb, M., \& Abdel Rahman, N. (2019). Why using organic fertilizers and biopesticides is important for food legumes production in Jordan? Advances in Environmental Biology, 13(1), 39-42.

[21] Muktamar, Z., Fahrurrozi, F., Dwatmadji, D., Setyowati, N., Sudjatmiko, S., \& Chozin, M. (2016). Selected macronutrients uptake by sweet corn under different rates liquid organic fertilizer in closed agriculture system. International Journal on Advanced Science Engineering and Information Technology, 6(2), 258-261.

[22] Nannette, R. (2011). Magnesium sulphate Hydrate (Epsomite) boosts growth in tomatoes, peppers and roses, how to use magnesium sulphate in the garden. http://voices.yahoo.com/magnesium-sulphatehydrate-epsomite-boostsgrowth-in-8638139.html?cat=6.

[23] Nemeskéri, E., \& Helyes, L. (2019). Review: physiological responses of selected vegetable crop species to water stress. Agronomy, 9, 447.

[24] Németh, S.Z., \& Ehret-Berczi, I. (2014). The Hungarian horticultural sector: Economic analysis of tomato greenhouse farms. Acta Horticulturae, 1041, 307-310.

[25] Patil, B., \& Chetan H. T. (2018). Foliar fertilization of nutrients. MARUMEGH, 3(1), 49-53.

[26] Premsekhar, M., \& Rajashree, V. (2009). Performance of hybrid tomato as influenced by foliar feeding of water soluble fertilizers. American - Surasian Yournal of Sustainable Agriculture, 3(1), 33-36.

[27] Racz, D., \& Radocz, L. (2020). The impact of applying foliar fertilizers on the health condition of maize. Acta Agraria Debreceniensis, 1, 105-109.

[28] Rengel, Z. (2020). Advances in foliar fertilizers to optimize crop nutrition. Chapter Taken From: Achieving Sustainable Crop Nutrition. Burleigh Dodds Science Publishing, Cambridge, UK.

[29] Savant, N.K., Snyder, G.H., \& Datnoff, L.E. (1997). Silicon management and sustainable rice production. Advances in Agronomy, 58, 151-199.

[30] Singh, J., Singh, M., Jain, A., Bhardwaj, S., Singh, A., Singh, D.K., Bhushan, B., \& Dubey, S.K. (2013). An introduction of plant nutrients and foliar fertilization: a review. Chapter 16. In Book: Precision Farming: A New Approach: Daya Publishing Company: New Delhi: India.

[31] Sonmez, S., Kaplan, M., Sonmez, N,K., Kaya, H., \& Uz, I. (2006). High level of copper application to soil and leaves reduce the growth and yield of tomato plants. Scientia Agricola. (Piracicaba, Braz.), 63(3), 213-218.

[32] Stern, V. M., Smith, R. F., van den Bosh, R., \& Hagen, K. S. (1959). The integration of chemical and biological control of the spotted alfalfa aphid (the integrated control concept). Hilgardia, 29(2), 81-101.

[33] Strey, R. (2020). PLANTIX Application, 3.3.0, 2020. Progressive Environmental \& Agricultural Technologies (PEAT GMBH), Germany.

[34] Wittwer, S.H., Bukovac, M.J. \& Tukey, H.B. (1963). Advances in foliar feeding of plant nutrients. In MHMcVickar, (Eds.), Fertilizer Technology and Usage. Soil Science Society of America, Madison, WI, 429-455.

[35] Woltz, S.S. Jones, J.P. \& Scott, J.W. (1992). Sodium chloride, nitrogen source, and lime influence fusarium crown rot severity in tomato. HortScience, 27(10), 1087-1088.

[36] Wright, D., \& Lenssen, A. (2013). Humic and fulvic acids and their potential in crop production. Department of Agronomy, Iowa State University.

[37] Yildirim, E. (2007). Foliar and soil fertilization of humic acid affect productivity and quality of tomato. Acta Agriculturae scandinavica, Section B - Soil and Plant Science, 57, 182-186. 